\title{
Os desafios dos docentes estrangeiros perante os constrangimentos atuais no ensino superior em Angola
}

\author{
The challenges of foreign teachers before current constraints
}

in higher education in Angola

\section{João Manuel Correia Filho'}

Taimara Roa Aleaga ${ }^{2}$

Filomena de Jesus Francisco Correia Filho Sacomboio ${ }^{3}$

Eufrázio dos Santos ${ }^{4}$

\section{Resumo}

A contemporaneidade, marcada pelo desenvolvimento vertiginoso da ciência nas diferentes esferas da vida, impõe aos centros educacionais a responsabilidade de graduar profissionais integrais, competentes, capazes de resolver os problemas que a sociedade enfrenta. Neste sentido, discute-se o estabelecimento de políticas educacionais que produzem mudanças na organização escolar tendo em conta os desafios que os profissionais encaram no desenvolvimento do processo de ensino e aprendizagem. Do impacto na identidade profissional poderá resultar um

\footnotetext{
1 Professor Auxiliar da Facultade de Serviço Social da Universidade de Luanda e Membro Investigador do Centro Interdisciplinar de História, Culturas e Sociedades (CIDHEUS) da Universidade de Évora. Doutor em Ciências da Educação -Especialidade em Formação Docentepela Universidade de Èvora. Email: jmcf82@yahoo.com.br

2 Professora Auxiliar no Instituto Superior Politécnico Atlântida. Mestre em Ciências da Educação Superior, pela Universidad Santiago de Cuba. Email: taimararoa21@gmail.com

3 Docente assistente do Instituto Superior de Tecnologias da Informação e Comunicação da Universidade de Luanda. Doutoranda em Tecnologia e Saúde pela Pontifícia Universidade Católica do Paraná. Email: filofilho@hotmail.com

${ }^{4}$ Docente Assistente da Facultade de Serviço Social da Universidade de Luanda. Doutorando em História, pela Faculdade de Letras e Ciências Socias da Universidade Agostinho Neto. Email: eufraziodosantos@hotmail.com
} 
crescimento do sistema educativo angolano. Assim, o presente texto tem por finalidade analisar o contributo dos docentes estrangeiros, perante os constrangimentos e desafios atuais no Ensino Superior em Angola. Para tal, realizou-se um estudo de natureza qualitativa, que se enquadra numa pesquisa analítica, explicativa e descritiva por meio da análise bibliográfica e documental sobre o Ensino Superior em Angola, desde a independência até à atualidade. Com isso, percebe-se que o subsistema de Ensino Superior em Angola é complexo, com lacunas a serem preenchidas, que precisam de maior motivação e empenho dos docentes, com particular realce para os quadros estrangeiros. Os desafios que se propõem estimulam a reflexões conducentes à formuluação de propostas de melhoria do alcance da qualidade de ensino.

Palavras-chave: Docentes estrangeiros; constrangimentos; desafios; Ensino Superior.

\section{Abstract}

Contemporaneity, marked by the dizzying development of science in different spheres of life, imposes on the educational centers the responsibility of graduating full-fledged, competent professionals, capable of solving the problems facing society. In this sense, the reality around the establishment of educational policies that produce changes in the school organization is discussed, taking into account the challenges that professionals face in the development of the teaching and learning process. Thus, due to the impact on professional identity, an increase in the Angolan educational system may result. Thus, the article aims to analyze the contribution of foreign teachers by proposing challenges for solving current problems of Higher Education in Angola. For this, it was necessary to carry out a qualitative study that fits into an analytical research with nature, explanatory and descriptive through bibliographic and documentary analysis on Higher Education in Angola from independence to the present. However, it is clear that Higher Education in Angola is a complex subsystem, with gaps to be filled, which need greater motivation and commitment on the part of the teachers in this teaching 
subsystem, with an emphasis on foreigners, therefore, the challenges that they propose stimulate reflections to reach teaching quality.

Keywords: Foreign teachers; constraints; challenges; Higher Education.

\section{Introdução}

O surgimento do Ensino Superior em Angola no ano de 1962 representa um marco significativo na historicidade do país, fruto de várias lutas contra o regime colonial e das mudanças que se verificava a nível internacional da necessidade de quadros qualificados. Deste modo, o seu surgimento, tal como das outras universidades em África, estava fortemente conexa à reprodução do sistema colonial determinado pela transferência das estruturas e modelos dos países colonizadores. Assim, o seu objetivo, era para dar resposta à necessidade da formação superior dos seus filhos residentes nas colónias e diminuir o clima hostil na época com início da luta armada em 1961 e poder, deste modo, conservar o domínio político, económico e administrativo da então colónia.

Neste sentido, o corpo docente era proveniente da «metrópole» que importava modelos coloniais e neocoloniais de formação com um ensino pouco contextualizado face a realidade que só mudou com a independência de Angola em 1975. Sendo assim, as mudanças na organização escolar precisavam de uma reconfiguração educativa, pois, o aumento de trabalho e da responsabilidade tendo em conta os resultados da aprendizagem obrigavam a existência de condições adequadas de trabalho.

O Subsistema do Ensino Superior em Angola carateriza-se em duas etapas no seu percurso histórico, de acordo com Carvalho (2012), reforçado por Filho (2020). A primeira corresponde ao período colonial, que vai de 1962 a 1974, considerado como a etapa do surgimento e desenvolvimento; a segunda começa com a independência, em 1975, até aos dias atuais, repartida em quatro fases importantes. Este artigo aborda a segunda etapa da Angola independente, 
refletindo sobre a cooperação dos docentes estrangeiros nas diferentes fases de desenvolvimento do Ensino Superior.

Para compreender esta etapa pós-colonial decorrente da periocidade do Ensino Superior em Angola, é fundamental ter em conta as abordagens de autores como Silva (2004), Carvalho (2012), Burity (2009), Kandingi (2016), Canga e Buza (2017), Filho (2020), Filho e Aleaga (2021), entre outros, que tratam de aspetos teóricos e práticos sobre o Ensino Superior em Angola. Nesta etapa, após a independência, os angolanos assumem a direção do sistema educacional com mudanças na orientação, tornando-se no centro das prioridades das políticas educacionais e do progresso social do país.

Considerando que o país era novo, faltava-lhe quase tudo, e a educação era uma prioridade para a formação do homem e, concomitantemente, para o desenvolvimento social. Todavia, o país não dispunha de quadros qualificados sufientes para atender à demanda de cidadãos ávidos de formação. Deste modo, o governo teve de recorrer à cooperação estrangeira em vários domínios, destacando-se o da educação, com a vinda dos chamados «professores cooperantes», provenientes de Cuba, Bulgária, da ex-URSS, Vietname, Portugal, ex-Zaíre, entre outros.

Portanto, o artigo tem por finalidade analisar o contributo dos docentes estrangeiros, perante os constrangimentos e desafios atuais no Ensino Superior em Angola. Para tal, foi necessário realizar um estudo de natureza qualitativa, enquadrado numa pesquisa analítica compreensiva e descritiva a partir da análise bibliográfica e documental sobre o Ensino Superior em Angola, desde a independência até à actualidade.

Assim sendo, o estudo está estruturado em três eixos fundamentais. 0 primeiro aborda a trajetória e o contributo dos docentes estrangeiros no Ensino Superior em Angola, o segundo tratou dos principais constrangimentos atuais a nível deste subsistema e por último discorreu-se sobre os desafios destes profissionais. 


\section{A trajetória e o contributo dos docentes estrangeiros no Ensino Superior em Angola}

Com a independência de Angola, muitos dos docentes que trabalhavam na universidade regressaram a Portugal, devido à situação político-militar que o recém-país ultrapassava. A falta de docentes para atuar neste subsistema de ensino foi gritante, obrigando o governo de Angola a estabelecer protocolos com diversos países cuja finalidade era a contratação de docentes estrangeiros para ajudarem na formação de quadros superiores no país.

Em base, as ideias de Flores (2003), quando se fala em formação de professionais, precisa-se de observar o ensino e refletir sobre o que represente ser docente num determinado cenário. Por tal razão, considera-se que o período contextualizado resulta essencial para analisar a identidade do professor, pois, estabelecem-se novos desafios aos indivíduos, às organizações e à sociedade.

Os acordos bilaterais resultaram na vinda de docentes estrangeiros, então chamados de cooperantes, provenientes de Cuba, Bulgária, Brasil, Roménia, França, Vietname, ex-União Soviética e do ex-Zaíre para trabalharem na Universidade de Angola, a única no país que representava o Ensino Superior e que, posteriormente, em 1985, se passou a chamar de Universidade Agostinho Neto. Para além dos acordos bilaterais com esses países, houve também contratos individuais com docentes de países como o Congo, África do Sul, Inglaterra, Itália, Mali, Suíça e Uruguai, entre outros.

Desta maneira, pode enquadrar-se a vinda de docentes estrangeiros em três etapas logo após a independência. A primeira enquadra-se no período que vai de 1977 a 1991, uma fase em que o país era caraterizado pelo Monopartidarismo e com uma orientação socialista quando se evidenciou a participação docente, como verifica-se no Quadro 1. 
Quadro 1. Total de docentes nacionais e estrangeiros por ano (1980 1991)

\begin{tabular}{|c|c|c|c|c|c|c|c|}
\hline \multirow[t]{2}{*}{ Docentes } & \multicolumn{6}{|c|}{ Anos de evolução } & \multirow[t]{2}{*}{ Total } \\
\hline & 1980 & 1981 & 1985 & 1987 & 1990 & 1991 & \\
\hline Nacionais & 104 & 117 & 277 & 320 & 411 & 495 & 1.724 \\
\hline Estrangeiros & 100 & 126 & 240 & 285 & 211 & 208 & 1.170 \\
\hline Total & 204 & 243 & 517 & 605 & 622 & 703 & 2.894 \\
\hline
\end{tabular}

Fonte: Fundação Gomes Teixeira (1996) e Fundação Calouste Gulbenkian (1987)

O Quadro 1 mostra a evolução do corpo docente. Nos primeiros anos desta etapa (1980 e 1987), tinha uma forte presença dos docentes estrangeiros, cuja missão não se restringia apenas à condução do processo de ensino e aprendizagem, mas também à criação e formação de quadro docente nacional capacitado para dar continuidade ao processo, como se observa a partir de 1985, onde a representatividade dos docentes nacionais aumenta, fruto desta cooperação. Cabe realçar que os docentes estrangeiros eram os que possuíam maior titulação, o que permitiu um crescimento qualitativo dos indicadores de diferenciação académica do corpo docente angolano, levando de oito (8) docentes doutores angolanos, em 1985, para vinte e um (21), em 1991, formados em diversos países (Fundação Calouste Gulbenkian, 1987).

Consequentemente, a cooperação estrangeira mostrou-se ser a base do crescimento do Ensino Superior em Angola, ajudando na criação de políticas educativas voltadas ao crescimento da identidade profissional. Deste modo, Castells (2008) considera que a identidade é edificada a partir da reestruturação de significados através das tendências sociais em correspondência com o tempo e espaço. Portanto, as reformas educacionais criaram mudanças na identidade dos professores e, desde esta perspetiva, os países que mais contribuíram foram Cuba e Portugal pela proximidade da língua e das relações históricas.

A segunda etapa começa de 1992 a 2001, assinalada pelas primeiras eleições multipartidárias que conduziram a democratização das instituições de 
ensino que é significativa e transmissora de uma dinâmica, que era resultado da aposta na diversificação da oferta de formação. Evidenciaram-se mudanças políticas, como a adoção da economia do mercado, dando cabimento à iniciativa privada, que permitiu o surgimento das universidades privadas. O Quadro 2 indica o decréscimo do número de docentes estrangeiros.

\section{Quadro 2. Decréscimo do corpo docente estrangeiro}

\begin{tabular}{|l|c|c|c|c|c|c|c|}
\hline \multirow{2}{*}{ Docentes } & \multicolumn{6}{|c|}{ Anos de evolução } & \multirow{2}{*}{ Total } \\
\cline { 2 - 7 } & $\mathbf{1 9 9 2}$ & $\mathbf{1 9 9 4}$ & $\mathbf{1 9 9 7}$ & $\mathbf{1 9 9 9}$ & $\mathbf{2 0 0 1}$ & $\mathbf{2 0 0 2}$ & \\
\hline Nacionais & 495 & 520 & 642 & 689 & 734 & 752 & 3.832 \\
\hline Estrangeiros & 208 & 67 & 96 & 70 & 105 & 117 & 663 \\
\hline Total & 703 & 587 & 738 & 759 & 839 & 869 & 4.495 \\
\hline
\end{tabular}

Fonte: Relatório da UAN, 2006, MESCT, 2012.

O Quadro 2 mostra o decréscimo dos docentes estrangeiros e um aumento dos docentes nacionais devido a vários fatores. O primeiro tem a ver com 0 período muito conturbado da década de 90 devido à explosão da guerra civil, criando instabilidade e falta de livre circulação principalmente no interior do país. O segundo consistiu na chamada "nacionalização da universidade", um projeto estratégico do governo angolano com a entrada de novos docentes que acabavam de regressar de bolsas de estudo de diversos países estrangeiros, a título de exemplo, em 1999, o Ensino Superior contava já com 100 doutores, comparativamente com os 21 em 1991.

Esta etapa é marcada pela forma da gestão da universidade, admitindo alterações, afastando-se do partido, principiando, assim, a democratização interna, num contexto plural de cultura e corporativismo profissional académico, promovendo, assim, a autonomia e a liberdade académica.

A terceira etapa vai de 2002, até à atualidade, sinalizada pelo memorando de entendimento do Luena, de que resulta a paz em Angola e o início da reconstrução do país. Assim sendo, sobressaiu um aumento expressivo de 
instituições de ensino superior públicas e privadas e, naturalmente, o aumento de docentes, quer nacionais, quer estrangeiros como se observa o Quadro 3.

Quadro 3. Alargamento do corpo docente estrangeiro no período de paz

\begin{tabular}{|l|c|c|c|c|c|}
\hline \multirow{2}{*}{ Docentes } & \multicolumn{5}{|c|}{ Anos de evolução } \\
\cline { 2 - 6 } & $\mathbf{2 0 1 4}$ & $\mathbf{2 0 1 5}$ & $\mathbf{2 0 1 6}$ & $\mathbf{2 0 1 7}$ & $\mathbf{2 0 1 8}$ \\
\hline Nacionais & 3329 & 7379 & 7071 & 8653 & 9340 \\
\hline Estrangeiros & 800 & 1281 & 1648 & 1545 & 1101 \\
\hline Total & 4129 & 8660 & 8719 & 10198 & 10441 \\
\hline
\end{tabular}

Fonte: Anuários Estatísticos de 2014, 2015, 2016, 2017, 2018, 2019

A estabilidade económica do país e a paz vai permitir o regresso e atração de muitos docentes estrangeiros para dar cobertura às novas instituições que iam surgindo em todas as províncias, como se pode observar na tabela acima onde se notou um aumento significativo a partir de 2014 a 2018, de acordo com os dados dos anuários estatísticos. Estiveram mais de 6.375 docentes estrangeiros de 46 países em que se resalta um número relevante de docentes de nacionalidade cubana e portuguesa a cooperar nas diferentes IES.

A essência da colaboração docente, de acordo com Day (2004), só existe quando há interação entre professores na planificação, na prática docente, na investigação e extensão, permitindo uma retroalimentação de saberes onde uns aprendem com os outros.A prestação de serviço dos docentes estrangeiros, como o paradigma da colaboração docente, apresenta-se, nos dias de hoje, como uma estratégia capaz de ajudar a dar resposta às mudanças educativas desejada, pelo que se concebe como uma das soluções para realizar mudanças educativas com sucesso.

\section{Principais constrangimentos atuais no ensino superior em Angola}

As implicações do Ensino Superior na contemporaneidade é analisado desde diferentes perspetivas, variando de contexto para contexto em correspondência 
com a história dos diversos sistemas de ensino, observando a sua organização, capacidade de reação e a implementação de políticas educativas. Perante isso, o sistema de Ensino Superior, em geral, e as IES, em particular, necessitam lidar conjuntamente com todos os desafios cada vez mais complexos que existem na atualidade.

Tal razão justifica que o entendimento da identidade tem uma conexão com as diferenças e igualdades e coincide-se com Ciampa (1985), quando refere que os indivíduos se vão diferenciar e igualar a partir dos grupos sociais a que pertencem os docentes, sejam nacionais, sejam estrangeiros. Por conseguinte, a identidade deve ser percebida como uma produção socio-histórica, que surge tendo em conta o contexto social.

Em Angola, desde o ano 2005, a Secretaria de Estado para o Ensino Superior (SEES) avaliou as instituições de tutela com o objetivo de verificar a qualidade dos serviços prestados pelos docentes e, deste modo, como documento final, traçaram-se as linhas-mestras para a melhoria da gestão deste subsistema. Nessa altura, os principais constrangimentos identificados estiveram relacionados, em primeiro lugar, com a conceção da instituição do Ensino Superior, onde se evidenciou que, além de estar contemplado o asseguramento delas, o défice de infraestrutura existente impossibilitou garantir a articulação harmoniosa do processo de ensino e aprendizagem, além do constrangimento referente ao financiamento das instituições, tendo em conta a gestão do subsistema.

Em várias IES, existiu uma disparidade entre a qualidade do ensino e os valores cobrados, em que foi evidente a fraca fiscalização no setor, levando, também, a que a implementação dos curricula não fosse aplicada de forma coerente, evidenciando-se nas instituições mais interesses económicos do que académicos, sendo este outro dos problemas verificados.

Relativamente à preparação didático-pedagógica dos docentes, percebeuse, também, que, além dos programas de agregação pedagógica desenvolvidos fundamentalmente para docentes em início de carreira, a maioria apresentava carências no seu desempenho, o que levou ao baixo nível de qualidade da 
formação. Para grande parte das IES privadas, o estudante era meramente um cliente que devia ser satisfeito de qualquer forma sem ter em conta a qualidade do processo de ensino-aprendizagem, o mais importante era o diploma, e não as competências alcançadas.

Assumindo a perspetiva de Roldão (2009), os docentes que trabalhavam de forma cooperativa em diferentes contextos sustentavam o seu trabalho a partir de sua valorização profissional, tendo em conta a promoção dos grupos, sua abertura inter-individual e o sentimento mútuo de segurança, tendo em conta a sua identidade profissional. As culturas cooperativas na prática profissional envolveram negociações, tomada conjunta de decisões, diálogo e aprendizagem por parte de todos os participantes nacionais e estrangeiros.

Desta forma, foi possível romper com modelos inflexíveis que levaram à mudança do perfil de formação, permitindo a qualificação dos docentes a nível do conhecimento, da capacidade de criatividade, da resolução de problemas, bem como do espírito de liderança multifuncional. Foi possível assumir que as relações com o outro geram também identidades sociais (Chamon, 2003), significando que a identidade profissional dos docentes, com enfases dos estrangeiros, se mostra nos sentimentos de pertença ao grupo em que estão inseridos e com o qual se identificam pelas práticas e saberes do exercício profissional.

Cabe realçar que, além das exigências académicas e os constrangimentos evidenciados no Ensino Superior a mais de quinze anos, muitos dos problemas apontados ainda se mantêm. Mas, não se deve descorar de inúmeros avanços em termos de massificação, infraestruturas, e outros. Apesar disso, continua a ser um tema prioritário pela sua importância nas transformações da sociedade, tendo em conta, de igual forma, a cooperação estrangeira.

Com base nas ideias de Fernandes (2004), assume-se que os profissionais docentes são pessoas que atuam no processo educativo em correspondência com paradigmas e desejos sociais, de igual forma, impregnam a sua marca pessoal na construção social da definição na qualidade do ensino. É ineludível o papel que desempenham na formação e no comportamento dos estudantes, quer pelos 
conhecimentos específicos da matéria, quer pela prática profissional. Na medida em que os docentes estrangeiros recém-chegados vão tendo apoio das IES, o seu desenvolvimento profissional será maior.

Em contra partida, é importante ter em conta que, em relação aos docentes, Nóvoa (1995) julga que a identidade, na época, se caraterizava por uma imagem, onde os docentes são vistos como indivíduos questionados desde diferentes situações. Isto quer dizer que, muitas vezes, não são considerados como profissionais competentes, para além de mostrarem um adequado nível de conhecimentos. Ressalte-se que são exigidos a terem relações sociais de forma geral com todos os intervenientes do processo, sem favorecer nenhum deles. De igual modo, não podem evidenciar uma vida pobre, mas devem evitar toda a ostentação.

Desde esta perspetiva, para os docentes estrangeiros, é imprescindível identificar-se com o povo de maneira amigável, pois desta maneira se favorecem os relacionamentos que contribuem para manter uma imagem positiva das IES, traduzida na satisfação do cumprir com sucesso da formação de profissionais competentes a partir do desenvolvimento das suas funções. A identidade do docente vai estar representada no trabalho que desenvolve em correspondência com o papel social concedido, a satisfação salarial e as condições básicas no serviço.

Finalmente, é necessário ter em conta que a cooperação docente é uma realidade universal, o que implica a sua progressiva diversificação. As IES precisam de criar mecanismos de apoio para a reconstrução dos caminhos educativos, por isso, quer nacionais quer estrangeiros precisam de mudanças na forma de pensar e se comportar nas diferentes áreas de atuação.

\section{Desafios dos docentes estrangeiros no Ensino Superior em Angola}

As grandes finalidades do desenvolvimento de um verdadeiro trabalho cooperativo docente são, entre outras, atingir com maior sucesso as aprendizagens desejadas, assim como potenciar as diversas competências dos 
futuros profissionais. Desta forma, existe maior probabilidade de haver progressos mais significativos, a partir da responsabilidade e reflexão partilhadas sobre a ação docente; o compromisso e aperfeiçoamento coletivos e a disponibilidade e postura crítica quanto ao trabalho conjunto realizado.

Tendo em conta as limitações existentes nos processos formativos, quer em IES públicas, quer em privadas, considera-se necessário valorizar mais a qualidade dos processos que se desenvolvem para evitar pessoal profissional carente e ineficaz. Deste modo, em correspondência com Georgen (2006, p. 69), assume-se que "a primeira e mais fundamental responsabilidade social da universidade refere-se à qualidade das atividades de investigação e de docência em qualquer área". Por isso, o docente universitário necessita de que os estudantes sejam hábeis em tomar decisões, liderar, resolver conflitos, utilizar conhecimentos adquiridos ao longo do processo académico; em outras palavras, sejam profissionais competentes de fato com uma formação humano, que favorece o desenvolvimento integral do cidadão.

Tendo em vista tais considerações a partir dos estudos feitos, percebe-se que, para além dos desafios que os docentes universitários em Angola estão sujeitos a enfrentar no âmbito das suas funções (ensino, investigação, gestão e extensão), postuladas no artigo $6 .^{\circ}$ do Estatuto da Carreira Docente Universitária, estatuída por meio do Decreto Presidencial n. ${ }^{0}$ 198/18, de Agosto. A par destes, os docentes estrangeiros têm de vencer outros desafios em particular a partir de sua própria identidade.

Nesta linha de pensamento, corrobora-se que, para estes docentes, além das dificuldades analisadas no ponto anterior, existem outras situações que se converteram em desafios perante os problemas atuais, como se comunicarem numa língua que dominam com limitações, compreendendo e adaptando-se às diferenças culturais. De igual forma, desprender-se numa cidade que desconhecem, adaptando-se a um espaço (hospedagem) que caiba no seu orçamento limitado. 
Por isso, os docentes estrangeiros precisam de organizar suas rotinas e cumprir com uma dinâmica diferente da vida, o que implica, também, o investimento de novas amizades, mantendo a estabilidade emocional e profissional na área de conhecimentos da carreira em função da contribuição do aperfeiçoamento de planos e programas analíticos, tendo em conta o caráter sistémico, flexível e diferenciado do processo de ensino-aprendizagem.

Deste modo, a sua formação didática e pedagógica deve estar em correspondência com o legislado pelo país, demonstrada na sua conduta com modéstia e simplicidade que possibilite a cooperação a partir do seu caráter problematizador, a fim de satisfazer as expetativas instrutivas e educativas dos estudantes. Isso facilitará a sua participação em júri e orientação dos estudantes com conhecimentos e flexibilidade perante as diversas conceções que existem no mundo da investigação, tendo em conta as particularidades do país, com aportes positivos, desde a sua experiência na integração e desenvolvimento de projetos de investigação e comunitários.

Desde esta perspetiva, resulta ser consequente com o processo de mudança do perfil docente, assim como contribuir para a publicação de livros didáticos, científicos e artigos em revistas imprensas ou eletrónicas que favoreçam o enriquecimento intercultural, profissional e científico de Angola fazendo uso adequado das tecnologias e línguas estrangeiras. Com isso, deve possuir capacidade de planificação, organização, execução e avaliação das atividades de ensino, investigação, gestão, internacionalização, inovação, etc. tendo em vista o alcance dos objetivos e finalidades do Ensino Superior em Angola.

No exercício da sua actividade, será necessário tomar decisões coerentes perante situações de legalidade e cumprimento de regulamentações, e outras disposições. Por conseguinte, deve respeitar-se a diversidade cultural no intercâmbio com a sociedade, possibilitando a melhoria das conceções e práticas curriculares, apresentando propostas de ações de extensão universitária como componentes extracurriculares que possibilitem a formação profissional de maneira integrada. 
Será importante prestar serviços e assistência à comunidade, tendo em conta contribuições para o aperfeiçoamento curricular, através da interdisciplinaridade e multidisciplinariedade de setores das IES. Sendo assim, será necessário a utilização de formas variadas de intervenção na busca de soluções razoáveis em função do contexto no ambiente positivo.

Cabe realçar que só com profissionais competentes ${ }^{5}$ será possível alcançar a qualidade da educação assimilada pelos estudantes, o que depende em grande medida, da qualidade do desempenho profissional, fundamentalmente dos docentes estrangeiros que cooperam nas IES. Tais razões justificam o aperfeiçoamento dos fundamentos teóricos e metodológicos que os futuros profissionais recebem.

É essencial compreender que os saberes do docente do Ensino Superior são cada vez mais atingidos pelas transformações e progressos sociais e, para os docentes estrangeiros, em particular, muitas questões constituem parte de suas curiosidades académicas, visto que a experiência da sociedade onde cooperam é diferente da vivenciada durante seus estudos ou desempenho profissional. As exigências são outras e elas acabam por competir com o próprio processo de ensino-aprendizagem.

Apesar dos desafios ora apresentados, é fundamental que as IES contribuam para a inserção desses profissionais, compreendendo que, para os docentes estrangeiros, o processo de ensino-aprendizagem é marcado por conceções diferentes, mas isso se converte em desafios perante as mudanças atuais que precisam assumir para que as adequações profissionais sejam efetivas.

Impõe-se adoptar um papel mediador entre os saberes dos estudantes e as informações pedagógico-didácticas e científicas que possui, relacionando-os de igual maneira com o mercado virtual. Os docentes estrangeiros do século XXI precisam de interpretações e metodologias inovadas perante a complexa sociedade onde decidiram cooperar.

\footnotetext{
${ }^{5}$ Aquele que possui conhecimento, habilidades e atitudes mobilizando-os com eficácia e eficiência de modo a resolver os problemas que lhe são imposto no seu dia-a-dia.
} 


\section{Considerações finais}

O Ensino Superior tem, cada vez mais, uma importância estratégica no desenvolvimento económico e social de Angola. Neste sentido, é preciso trabalhar nos desafios impostos pela sociedade atual, preparando os seus profissionais. Sendo assim, as IES devem aproveitar a experiência dos docentes estrangeiros, na construção da formação integral de cidadãos a partir de sua identidade profissional.

Em face da importância destes aspetos, acentua-se a necessidade das IES de contribuir mediante a formação de grupo multidisciplinar capaz de satisfazer as prioridades dos docentes estrangeiros a partir do aperfeiçoamento do idioma, dos estímulos emocionais tendo em conta uma maior proximidade com a nova realidade em dependência das particularidades específicas de cada caso. Por conseguinte, torna-se compreensível que eles se consigam enquadrar com rapidez e em melhores condições no novo contexto.

Portanto, as demandas para este nível de ensino são cada vez maiores, por isso o processo de ensino-aprendizagem precisa de ser ampliado e compreendido pelos docentes nacionais e estrangeiros, em função do confronto entre ideias, compreensões, equívocos, que devem ser considerados e atendidos de forma inovadora para assegurar a construção dos conhecimentos de forma consciente e transformadora.

Finalmente, torna-se necessário os docentes estrangeiros unirem os conhecimentos adquiridos por meio de sua formação académica em correspondência com a realidade do país, tendo em conta que cada espaço, a partir de suas funções, constitui experiências únicas com base nos desafios anunciados para reforçar a qualidade do Ensino Superior em Angola. 


\section{Referências bibliográficas}

Angola. Decreto Presidencial n. ${ }^{\circ}$ 191/18, de 08 de Agosto de 2018 - publicado no Diário da República. I Série n. 118 - aprova o Estatuto da Carreira Docente do Ensino Superior.

Burity, S. (2009). Repensar a Profissionalização em Ciências da Educação. Luanda, Angola: ESDA/JAM.

Canga, J.L. e Buza, A.G. (2017). Gestão do Ensino Superior em Angola os desafios endógenos e exógenos. Conferência do Forum da Gestão do Ensino Superior nos países e Regióes de Língua Portuguesa (pp. 51-62). Universidade de Coimbra: Forges 5.

Carvalho, P. (2012). Evolução e Crescimento do Ensino Superior em Angola. Instituto Universitário de Lisboa (ISCTE-IUL), Lisboa: Centro de Estudos Africanos.

Castells, M. (2008). O poder da identidade. São Paulo: Paz e Terra.

Chamon, E.M.Q.O. (2003). Formação e (re) construção identitária: estudo das memórias de professores do ensino básico inscrito em um programa de formação continuada. Tese (Pós-Doutorado em Educação) - Faculdade de Educação, Universidade Estadual de Campinas, Campinas.

Ciampa, A.C. (1985, pp.58-75). Identidade. En W. Codo e S. T. M Lane (Orgs.), Psicologia social: o homem em movimento. 3. ${ }^{a}$ ed. São Paulo: Brasiliense.

Day, C. (2004). A Paixão pelo Ensino. Porto: Porto Editora.

Fernandes, M.C.G. (Nov-2004). Escolha profissional e prática docente: o discurso de professores do ensino superior privado. 27. a Reunião da ANPED, Caxambu MG.

Filho, J.M.C. (2020). O perfil do docente universitário em Angola no século XXI, suas perspetivas e desafios: Um estudo exploratório em torno de conceções e de práticas (Tese de Doutoramento). Évora: Instituto de Investigação e Formação Avançada Universidade de Évora. 
Filho, J.M.C., Aleaga, T.R. e Sacomboio, F.d. (2021). A historicidade do ensino superior desde a génese até à actualidade: suas transformações e impacto no sistema educativo angolano. Revista Educación, Política y Sociedad, 6(1), 177-202. Flores, M. A. (2003, pp. 83-103). Dilemas e desafios na formação de professores. En M.C. Moraes, J.A. Pacheco e M.O. Evangelista (Orgs.), Formação de professores: perspetivas educacionais e curriculares. Porto: Porto Editora.

Fundação Calouste Gulbenkian (1987). Universidade Agostinho Neto. Estudo Global. Lisboa: Fundação Calouste Gulbenkian.

Fundação Gomes Teixeira (1996). Contributos para a Revitalização da Universidade em Angola. Porto: Publicações da Universidade do Porto.

Gabinete do Plano do Ministério da Educação (1990). Anuário Estatístico 1985/85 a 1989/90. Luanda: Ministério da Educação.

Georgen, P. (2006). Universidade e compromisso social. In: Ristoff, D; Savegnani, P. Universidade e compromisso social. Brasília: Instituto Nacional de Estudos e Pesquisas Educacionais Anísio Teixeira.

Kandingi, A. (2016). A expansão do ensino superior em angola. Um estudo sobre impacte das instituições de ensino superior privado (Tese de Doutoramento). Lisboa: Universidade Nova de Lisboa.

Ministério do Ensino Superior, Ciência e Tecnologia - MESCT - (2012). Rede de instituições de ensino superior em Angola. Dados estatísticos. Luanda: MESCT.

Ministério do Ensino Superior, Ciência e Tecnologia - MESCT - (2014, 2015, 2016, 2017, 2018). Anuários Estatísticos do Ensino Superior em Angola.

Roldão, C. (2007). Colaborar é preciso - Questões de qualidade e eficácia no trabalho dos professores. Lisboa: Ministério da Educação -DGIDC.

Roldão, C. (2009). Estratégias de ensino: o saber e o agir do professor. V. N. Gaia: Fundação Manuel Leão

SEES (2005). Linhas Mestras para a melhoria de gestão do Subsistema do Ensino Superior. Secretaria de Estado Para o Ensino Superior, CDI/SEES, Luanda. 
SEES (2006). Plano de Implementação das Linhas Mestras para a melhoria de gestão do Subsistema do Ensino Superior. Secretaria de Estado Para o Ensino Superior, CDI/SEES, Luanda.

Silva, A. E (2004). O Burocrático e o Politico na Administracão Universitária. Comunidades e rupturas na gestao dos recursos humanos docentes na Universidade Agostinho Neto (Angola) (Tese de Doutoramento). Braga: Instituto de Educação e Psicologia / Universidade de Minho.

Universidade Agostinho Neto (U.A.N.) (2002-2006). Relatório Anual. Luanda: Universidade Agostinho Neto. 